\title{
Bioactive Compounds, Antioxidant Activity and Nutritional Quality of Different Culinary Aromatic Herbs
}

\author{
Violeta NOUR $^{1 *}$, Ion TRANDAFIR ${ }^{2}$, Sina COSMULESCU ${ }^{1}$ \\ ${ }^{1}$ University of Craiova, Department of Horticulture and Food Science, 13 A.I. Cuza Street, 200585 Craiova, \\ Romania; vionor@yahoo.com (*correspondingauthor); sinacosmulescu@hotmail.com \\ ${ }^{2}$ University of Craiova, Department of Chemistry, 107 Calea Bucuresti Street, 200529 Craiova, Romania; nelutrandafir@yahoo.com
}

\begin{abstract}
In the present work, four of the most widely used culinary herbs (parsley, dill, lovage and celery leaves) in the Romanian traditional cuisine were assessed for some nutritional quality parameters (moisture content, titratable acidity, ascorbic acid content and mineral content), total phenolics content, total flavonoids content and antioxidant activity by 1,1-diphenyl-2picrylhydrazyl (DPPH) radical scavenging assay. In addition, high-performance liquid chromatography (HPLC) coupled with diode-array detection was applied for the identification and quantification of some individual phenolic compounds in the selected aromatic herbs. Although parsley showed the highest ascorbic acid content $(206.32 \mathrm{mg} / 100 \mathrm{~g} \mathrm{fw})$, it registered the lowest antioxidant activity. Fresh lovage recorded the highest total phenolic content ( $577.04 \mathrm{mg} \mathrm{GAE} / 100 \mathrm{~g}$ ), total flavonoids content $(298.38 \mathrm{mg} \mathrm{QE} / 100 \mathrm{~g})$ and antioxidant activity, followed by dill and celery leaves. Among the identified phenolic acids, ellagic acid was predominant in lovage and celery leaves whereas sinapic and vanillic acids were prevalent in dill. Among flavonoids, myricetin was predominant in parsley and celery leaves whereas rutin was predominant in dill and lovage.
\end{abstract}

Keywords: antioxidant activity, ascorbic acid, celery leaves, dill, flavonoids, lovage, parsley, phenolic acids

\section{Introduction}

Spices are essentially used to improve the appeal and sensory characteristics of food. Extensive experiments have proved the health benefits of spices without any deleterious side-effects (Gunasekar $e$ t al., 2012). The aromatic herbs used in flavouring food and beverages are also sometimes included as spices. They have been grown and used for hundreds of years, and they are becoming increasingly popular for their ability to enhance and complement the flavors of a wide variety of foods (Zheng and Wang, 2001). Culinary aromatic herbs are good sources of essential nutrients such as vitamins and minerals as well as antioxidant compounds. Supplementation of diet with various herbs is recommended among individual consumers, both for its healing properties and nutritive value (Yen et al., 2002). Numerous studies have shown that a high intake of vegetables that are sources of antioxidant compounds is associated with a lower incidence of cardiovascular disease, cancer and other chronic diseases. The relatively low intake levels of culinary herbs and spices do not necessarily mean that they are of little value as their high polyphenol content, and thus ultimately the potential biological impact of this content, cannot be ignored (Opara and Chohan, 2014).
The bioactive compounds, which are the key natural flavour and fragrance ingredients of various spices and other aromatic plants, play a vital role in healthcare (Gunasekar $e t a l$., 2012). Herbs and spices are a dietary source of bioactive polyphenols (Hinneburg et al., 2006), which are now known to possess beneficial effects for human health, including digestive stimulant, anti-inflammatory, antimicrobial, antioxidant and anticarcinogenic activities (Shobana and Akhilender Naidu, 2000; Zheng and Wang, 2001). In addition to phenolic compounds, these aromatic herbs contain numerous phytochemicals such as nitrogen compounds, carotenoids, and ascorbic acid. Many of these phytochemicals possess significant antioxidant capacities that are associated with lower incidence and lower mortality rates of cancer in several human cohorts (Zheng and Wang, 2001). Moreover, the volatile constituents (essential oils) that are the main cause for use of these plants can significantly contribute to biological activity (Inouye et al., 2001).

Recently, there has been growing awareness of the importance of a high dietary content of phenolic compounds, such as flavonoids and hydroxycinnamic acids (VallverduQueralt et al., 2014), because of their apparent multiple biological effects, including metal chelation, free-radical scavenging, inhibition of cellular proliferation, modulation of enzymatic activity and signal transduction pathways (Del Rio $e t$ al., 2013). 
180

In recent years, the search of natural and safe antioxidants, especially of plant origin has increased considerably, mainly because synthetic antioxidants such as butylated hydroxyltoluene (BHT) or butylated hydroxyanysol (BHA) have been confirmed or suspected to be associated with potential health hazards (Hinneburg et al., 2006). Therefore, searching for natural antioxidants from herbs or plants, to attenuate oxidative and nitrosative stress, is of growing interest (Wu et al., 2011).

In this study there were selected four widely used aromatic herbs in the traditional Romanian cuisine, which are known to possess strong pharmacological activity and high antioxidant content: dill, parsley, lovage and celery leaves. They were tested for their content of biologically active compounds (ascorbic acid, phenolic compounds, and flavonoids) and their antioxidant activity. Another purpose of this study was to indentify and quantify some individual phenolic compounds in these aromatic herbs using high performance liquid chromatography (HPLC) coupled with diode-array detection.

\section{Materials and Methods}

\section{Chemicals and reagents}

Folin-Ciocalteu reagent (2 N), 6-hydroxy-2,5,7,8tetramethylchroman-2-carboxylic acid (Trolox), HPLC grade acetonitrile, acetone, $n$-hexane and methanol were purchased from Merk (Germany). Gallic acid (99\% purity), anhydrous sodium carbonate ( $99 \%$ purity), aluminium nitrate, potassium acetate, acetic acid, quercetin and 2,2-diphenyl-1-picrylhydrazyl (DPPH, 90\% purity) were from Sigma-Aldrich (Germany). Standards of phenolic acids (gallic, vanillic, chlorogenic, caffeic, syringic, $p$-coumaric, ferulic, sinapic, salycilic, ellagic and transcinnamic) and flavonoids (catechin, epicatechin, rutin, myricetin and quercetin) were also purchased from Sigma-Aldrich. Ultrapure water was obtained from a Milli-Q water purification system (TGI Pure Water Systems, USA).

\section{Plant material}

Fresh plant materials of dill (Anethum graveolens), parsley (Petroselinum crispum), lovage (Levisticum officinale) and celery (Apium graveolens $\mathrm{L}$.) leaves were purchased from a local market in Craiova, Romania. Samples were washed under tap water and inedible parts were removed. Samples were frozen at $-20{ }^{\circ} \mathrm{C}$ until analysis. For quality parameters analyses (moisture content, titratable acidity, ascorbic acid content), sub-samples were stored at $4^{\circ} \mathrm{C}$ and used the day after.

Nutritional quality parameters (moisture content, titratable acidity)

Moisture content (\%) was determined gravimetrically by drying the samples to a constant weight at $105^{\circ} \mathrm{C}$ in a laboratory oven (Memmert, Germany). Titratable acidity (as \% citric acid) was measured by titrating the water plant extracts with $0.1 \mathrm{~N}$ $\mathrm{NaOH}$ solution using phenolphthalein as indicator.

\section{Ascorbic acid content}

$5 \mathrm{~g}$ of whole plant product were homogenized to puree in a porcelain mortar and diluted to $100 \mathrm{ml}$ with $0.1 \mathrm{~N} \mathrm{HCl}$. After 30 minutes the extraction solution was centrifuged at $4200 \mathrm{rpm}$ for 10 minutes. The supernatant was filtered through $0.45 \mu \mathrm{m}$ pore size filter and injected into a Surveyor Thermo Electron system equipped with a Diode Array Detector (DAD) and a reverse-phase C18 column (Hypersil Gold aQ, $25 \mathrm{~cm} \times 4.6 \mathrm{~mm}$, $5 \mu \mathrm{m}$ ) maintained at $10{ }^{\circ} \mathrm{C}$. Elution (flow rate of $0.7 \mathrm{~mL} / \mathrm{min}$ ) was performed in isocratic conditions. The mobile phase consisted of a phosphate buffer solution $\left(50 \mathrm{mM} \mathrm{KH}_{2} \mathrm{PO}_{4}\right.$ in water) adjusted to a $\mathrm{pH}$ value of 2.8 . The absorbance was measured at $254 \mathrm{~nm}$ and the ascorbic acid peak area was quantified with the Chrom Quest 4.2 software on the basis of an external standard calibration curve $(0-50 \mathrm{mg} / \mathrm{L})$. Ascorbic acid content was expressed as $\mathrm{mg} / 100 \mathrm{~g}$ fresh weight ( $\mathrm{fw}$ ).

\section{Minerals content}

Calcium $(\mathrm{Ca})$, magnesium $(\mathrm{Mg})$, sodium $(\mathrm{Na})$ and potassium $(\mathrm{K})$ were determined by microwave digestion followed by inductively coupled plasma mass spectrometry (ICPMS). Samples of approximately $2.0 \mathrm{~g}$ were weighed in TFM vessels, over that $5 \mathrm{~mL}$ nitric acid $65 \%$ and $2 \mathrm{~mL}$ hydrogen peroxide $30 \%$ were added. The vessels were then closed and heated at $180{ }^{\circ} \mathrm{C}$ for $20 \mathrm{~min}$ in the Milestone digestion microwave system. Reagent blanks were included in each series of digestions. After digestion was completed, the clear, colourless solution was transferred into a $50 \mathrm{~mL}$ volumetric flask and diluted to the mark with ultrapure water. The sample solutions were stored in polyethylene vials at $6{ }^{\circ} \mathrm{C}$ until analysis. An Elan 9000 inductively coupled plasma mass spectrometer (Perkin Elmer Sciex, Canada) equipped with Meinhard nebulizer and Scott-type double-pass spray chamber was used throughout. Calibration standards were prepared by serial dilution of commercially prepared analytical standard solutions (PerkinElmer, Shelton, CT) and linear calibration curves were established for concentration vs. absorbance. The results were expressed in mg per $100 \mathrm{~g}$ of fresh weight.

\section{Extraction ofphenolic compounds}

For the analysis of total phenolics, total flavonoids and antioxidant activity, samples $(1.5 \mathrm{~g})$ were extracted with $10 \mathrm{~mL}$ methanol in a Bandelin Sonorex Digital 10P ultrasonic bath (Bandelin Electronic GmbH, Germany) for $60 \mathrm{~min}$ at room temperature. Supernatants were collected, filtered through 0.45 $\mu \mathrm{m}$ polyamide membranes and used for the assays.

\section{Totalphenolics content}

The total phenolics content was assessed by using the FolinCiocalteu phenol reagent method according to the method of Singleton and Rossi (1965) with minor modifications (Cosmulescu et al., 2015). Briefly, $1 \mathrm{~mL}$ of each methanolic extract (diluted 1:10 with methanol) was mixed with $1 \mathrm{~mL}$ distilled water and $500 \mu \mathrm{L}$ Folin-Ciocalteau reagent and stirred for one minute. After $2 \mathrm{~min}, 4 \mathrm{~mL}$ of $7.5 \%$ sodium carbonate aqueous solution were added and the mixture was incubated for 2 hours at $25^{\circ} \mathrm{C}$. The same procedure was also applied to the standard solutions of gallic acid. Finally, the absorbance of the mixture was measured at $765 \mathrm{~nm}$ using an Evolution 600 UV/VIS spectrophotometer (Thermo Scientific, USA). Gallic acid was used for preparing the standard curve $(0-100 \mathrm{mg} / \mathrm{L})$ and the results were expressed as milligrams of gallic acid equivalents (GAE) per $100 \mathrm{~g}$ of fresh weight.

\section{Total flavonoids content}

The total flavonoids content was measured using the aluminium nitrate colorimetric method (Mohammadzadeh $e t$ al., 2007). Briefly, $0.5 \mathrm{~mL}$ of each methanolic extract (diluted 
$1: 10$ with methanol) was mixed in a test tube with $0.1 \mathrm{~mL}$ of $10 \%$ aluminum nitrate, $0.1 \mathrm{~mL}$ of $1 \mathrm{M}$ aqueous potassium acetate and $4.3 \mathrm{~mL}$ methanol. The reactive solution was well mixed and allowed to stand for $40 \mathrm{~min}$ at room temperature before the absorbance at $415 \mathrm{~nm}$ was measured using an Evolution 600 UV/VIS spectrophotometer (Thermo Scientific, USA). Quercetin was used for preparing the standard curve (0$100 \mathrm{mg} / \mathrm{L})$. The results were expressed as milligrams of quercetin equivalents $(\mathrm{QE})$ per $100 \mathrm{~g}$ of fresh weight.

\section{DPPH radical-scavenging activity}

The radical scavenging activity was evaluated in the methanolic extracts using the DPPH (2, 2-diphenyl-1-picrylhydrazyl) assay as described by Oliveira et al. (2008), with some modifications. Briefly, each methanolic extract $(50 \mu \mathrm{L})$ was mixed with $3 \mathrm{~mL}$ of methanolic solution containing $0.004 \%$ (v/v) DPPH. The mixture was shaken vigorously and kept in the dark for $30 \mathrm{~min}$. The absorbance was then read at $517 \mathrm{~nm}$ using an Evolution $600 \mathrm{UV}-\mathrm{V}$ is spectrophotometer (Thermo Scientific, USA). The radical scavenging activity was calculated as a percentage of DPPH inhibition using the following formula:

$$
\text { DPPH scavenging activity }(\%)=\left[1-\mathrm{As}_{\mathrm{s}} / \mathrm{A}_{\text {blank }}\right] \times 100,
$$

where As represents the absorbance of the sample extract with DPPH and Ablank is the absorbance of the DPPH solution without sample. The DPPH scavenging activity was subsequently calculated with respect to the 6-hydroxy-2,5,7,8tetramethylchroman-2-carboxylic acid (Trolox), which was used as a standard reference. Results were expressed as milligrams of Trolox equivalents per $100 \mathrm{~g}$ of fresh weight. All assays were conducted in triplicate.

\section{Phenolicprofile}

Identification and quantification of phenolic compounds was achieved using reversed-phase HPLC according to the method developed by Nour et al., (2013). The analysis was performed using a Finningan Surveyor Plus HPLC system (Thermo Electron Corporation, San Jose, CA) coupled to a diode array detector and equipped with a reversed-phase Hypersil Gold C18 column $(5 \mu \mathrm{m}, 250 \times 4.6 \mathrm{~mm})$. The mobile phase consisted of $1 \%$ aqueous acetic acid solution (A) and methanol (B). Samples were eluted with the following gradient: 0-27 min 90\% A, 27-55 min 90-60\% A, 55-60 min 60\% A, 60$62 \min 60-56 \%$ A, $62-70 \min 56 \%$ A, $70-71 \mathrm{~min} 56-90 \%$ A, and $71-75 \mathrm{~min} 90 \% \mathrm{~A}$. The flow rate was $1 \mathrm{~mL} / \mathrm{min}$ and injection volume was $5 \mu \mathrm{L}$. Column temperature was maintained at $20^{\circ} \mathrm{C}$. Chromatograms were acquired at three different wavelengths (254, 278 and $300 \mathrm{~nm}$ ) according to absorption maxima of analyzed compounds. Each compound was quantified according to the peak area measurements, which were reported in calibration curves of the corresponding standards. The content of investigated phenolic compounds was expressed in mg per 100 gof fresh weight.

\section{Statistical analysis}

The measurements were performed in triplicate for each sample and results were expressed as mean value \pm standard deviation. Correlations were estimated using Pearson's correlation coefficient $(\mathrm{r})$. Statistical analysis was performed using Statgraphic Centurion XVI software (StatPoint Technologies, Warrenton, VA, USA).

\section{Results and Discussion}

The moisture content, the titratable acidity and the ascorbic acid content of the selected culinary aromatic herbs are shown in Table 1. The moisture content of fresh herbs analyzed was high, with values above $82 \%$. Because of the high moisture content, these aromatic herbs are susceptible to degradation which can render the product unsuitable for consumption. In order to inhibit microorganism growth and prevent degradation, aromatic herbs are ordinarily dried for market using different methods (Kamel et al., 2013).

The moisture content was higher in dill $(87.68 \%)$ and parsley $(85.44 \%)$ and lowest in celery leaves (82.14\%). These values are in good agreement with those reported by Kamel et al. (2013) who found $87.58 \%, 83.4 \%$ and $84.75 \%$ in dill, parsley and celery leaves respectively, while Leahu et al. (2013) determined a moisture content of $82.25 \%$ in dill and $83.24 \%$ in parsley.

Titratable acidity recorded low levels, i.e. between 0.096 and $0.128 \%$ as citric acid in parsley, dill and celery leaves, and slightly higher $(0.192 \%$ as citric acid $)$ in lovage, amounts which are low in comparison to fruits.

The highest content of ascorbic acid was determined in fresh parsley $(206.32 \mathrm{mg} / 100 \mathrm{~g})$, followed by lovage $(110.41$ $\mathrm{mg} / 100 \mathrm{~g})$, celery leaves $(89.57 \mathrm{mg} / 100 \mathrm{~g})$ and dill (63.69 $\mathrm{mg} / 100 \mathrm{~g})$. Higher values of ascorbic acid content were reported by Leahu et al. (2013) in parsley $(347.6 \mathrm{mg} / 100 \mathrm{~g})$ and dill (150 mg/100 g), Zenoozian (2011) determined 130 $\mathrm{mg}$ ascorbic acid/100 $\mathrm{g}$ in parsley and $40 \mathrm{mg} / 100 \mathrm{~g}$ in dill while Sakaldaş et al. (2010) found $55.4 \mathrm{mg} / 100 \mathrm{~g}$ ascorbic acid in fresh dill leaves. Lisiewska et al. (2006) have shown that, depending on the usable part, the content of vitamin $\mathrm{C}$ varied within the range of $29 \mathrm{mg}$ in $100 \mathrm{~g}$ dill stems $60 \mathrm{~cm}$ in height to $186 \mathrm{mg}$ in $100 \mathrm{~g}$ leaves of dill plants $20 \mathrm{~cm}$ in height. The same authors have shown that in all parts of dill plants, with the exception of petioles, the content of vitamin $C$ decreased with plant growth.

Results on total phenolics content, total flavonoids content and antioxidant activity are presented in Table 2 . The total phenolic content of the selected aromatic plants was higher in the order: lovage $>$ dill $>$ celery leaves $>$ parsley, and signifficant differences were found among them.

Dill presented total phenolics content of $418 \mathrm{mg} \mathrm{GAE} / 100$ g while parsley presented the lowest content, i.e. $360.89 \mathrm{mg}$ $\mathrm{GAE} / 100 \mathrm{~g}$ fw. Levels of phenolic compounds found in parsley and dill were higher than those reported by Opara and Chohan (2014), ie $89.27 \mathrm{mg} \mathrm{GAE} / 100 \mathrm{~g}$ in parsley and $208.18 \mathrm{mg}$ GAE/100 $\mathrm{g}$ in dill, but lower than those presented by Shan $e t$ al. (2005) ie $636 \mathrm{mg} \mathrm{GAE} / 100 \mathrm{~g}$ fw in dill and $631 \mathrm{mg} / 100 \mathrm{~g}$ fw in parsley or Číz et al. (2010) who reported a total phenolic content of $599.7 \mathrm{mg} \mathrm{GAE} / 100 \mathrm{~g}$ in parsley but only $150.4 \mathrm{mg}$ GAE/100 g in dill. Lisiewska et al. (2006) determined only

Table 1. Moisture content, titratable acidity and ascorbic acid content of the selected aromatic herbs

\begin{tabular}{cccc}
\hline Herbs & $\begin{array}{c}\text { Moisture } \\
\text { content }(\%)\end{array}$ & $\begin{array}{c}\text { Titratable acidity } \\
(\% \text { citric acid })\end{array}$ & $\begin{array}{c}\text { Ascorbic acid } \\
(\mathrm{mg} / 100 \mathrm{~g} \mathrm{fw})\end{array}$ \\
\hline Parsley & $85.44 \pm 0.65$ & $0.128 \pm 0.02$ & $206.32 \pm 3.26$ \\
Dill & $87.68 \pm 0.82$ & $0.096 \pm 0.01$ & $63.69 \pm 1.26$ \\
Lovage & $84.92 \pm 0.46$ & $0.192 \pm 0.02$ & $110.41 \pm 2.33$ \\
Celery leaves & $82.14 \pm 0.98$ & $0.128 \pm 0.01$ & $89.57 \pm 1.89$ \\
\hline
\end{tabular}


Table 2. Total phenolic content, total flavonoids content and antioxidant activity of selected culinary aromatic herbs

\begin{tabular}{cccc}
\hline Herbs & $\begin{array}{c}\text { Total phenolics content } \\
(\mathrm{mg} \mathrm{GAE} / 100 \mathrm{~g})\end{array}$ & $\begin{array}{c}\text { Total flavonoids content } \\
(\mathrm{mg} \mathrm{QE} / 100 \mathrm{~g})\end{array}$ & $\begin{array}{c}\text { Antioxidant activity } \\
(\mathrm{mg} \text { Trolox } / 100 \mathrm{~g})\end{array}$ \\
\hline Parsley & $360.89 \pm 15.41$ & $260.55 \pm 9.56$ & $987.51 \pm 14.34$ \\
Dill & $418.09 \pm 12.28$ & $110.06 \pm 4.45$ & $1125.93 \pm 18.67$ \\
Lovage & $577.04 \pm 24.30$ & $298.38 \pm 11.38$ & $1462.52 \pm 28.88$ \\
Celery leaves & $403.84 \pm 18.34$ & $156.89 \pm 5.56$ & $1088.64 \pm 11.35$ \\
\hline
\end{tabular}

between 197 and $331 \mathrm{mg} \mathrm{GAE} / 100 \mathrm{~g}$ in dill and showed that the content of polyphenols increased with the increasing height of the plant.

Lovage presented the highest total phenolics content (577.04 mg GAE/100 g fw) and the highest antioxidant activity (1462.52 mg Trolox/100 g). The highest content of flavonoids was also determined in lovage $(298.38 \mathrm{mg} \mathrm{QE} / 100$ $\mathrm{g}$ ), demonstrating the outstanding value of this culinary herb, widely used in the traditional Romanian cuisine, in terms of antioxidant activity and content of bioactive compounds. Compared with this result, Zheng and Wang (2001) reported a total phenolics content of $263 \mathrm{mg} \mathrm{GAE} / 100 \mathrm{~g}$ in lovage, while Ćíz et al. (2010) reported $267 \mathrm{mg} \mathrm{GAE} / 100 \mathrm{~g}$.

Celery leaves presented also a high total phenolics content (403.84 mg GAE/100 g) and total flavonoids content (156.89 $\mathrm{mg} / 100 \mathrm{~g}$ ). Kiselova et al. (2006) reported that, in the traditional phytotherapy, wild celery leaves were used as diuretic, antirheumatic and stimulant to the central nervous system in cases of impotence while Chanwitheesuk et al. (2005) presented the uses of celery leaves as reconstructive, carminative and uretic. Kiselova et al. (2006) reported a total phenolic content of $129.39 \mu \mathrm{M} \mathrm{QE} / 100 \mathrm{~g}$, Chanwitheesuk $e t$ al. (2005) determined only $31.1 \mathrm{mg} / 100 \mathrm{~g}$ while Čiž et al. (2010) reported a total phenolic content of $605.5 \mathrm{mg}$ $\mathrm{GAE} / 100 \mathrm{~g}$ in celery leaves.

The methanolic extracts of the selected aromatic herbs showed extremely high values of the antioxidant activity, which ranged between 987.5 and $1462.5 \mathrm{mg}$ Trolox/100 g (Table 2).
Although parsley presented the highest ascorbic acid content, it registered the lowest antioxidant activity, probably due to the lower content of phenolic compounds. However, Fejes et al. (2000) found a considerable antioxidant activity against lipid peroxidation for the methanolic extracts from parsley leaves.

The highest antioxidant activity was recorded in lovage, followed by dill and celery leaves, following the same ranking order as for total phenolics content. Besides, a good correlation was found between total phenolic content and antioxidant activity in the four aromatic herbs analyzed $(r=0.92)$.

Culinary herbs and spices are of interest for their content of bioactive compounds that may exert beneficial effects on human health. Table 3 presents a list of 16 phenolic compounds identified and quantified in this study by HPLCDAD in the aromatic herbs analysed. Phenolic compounds were identified by comparing retention times with those of the corresponding standards. Considerable variation was found in phenolic compounds of the selected aromatic herbs. The predominant class/group of polyphenols in herbs and spices are the phenolic acids and flavonoids (mainly the flavone and flavonol sub-groups) (Opara and Chohan, 2014).

In many herbs, the main flavonoid constituents are flavonol aglycones such as quercetin, myricetin, kaempferol, and their glycosides. Parsley presented a high total flavonoid content (260.55 mg QE/100 g), value in good agreement with the high content of myricetin $(151.03 \mathrm{mg} / 100 \mathrm{~g})$ and quercetin $(71.33$ $\mathrm{mg} / 100 \mathrm{~g}$ ) recorded in parsley.

Table 3. Phenolic compounds in selected culinary aromatic herbs ( $\mathrm{mg} / 100 \mathrm{~g}$ fresh weight)

\begin{tabular}{ccccc}
\hline Compound & Parsley & Dill & Lovage & Celery leaves \\
\hline Gallic acid & $0.75 \pm 0.03$ & $0.93 \pm 0.04$ & $0.44 \pm 0.02$ & $3.29 \pm 0.13$ \\
Catechinhidrate & $3.19 \pm 0.13$ & nd & $3.65 \pm 0.18$ & $4.06 \pm 0.21$ \\
Vanillic acid & $2.79 \pm 0.09$ & $31.96 \pm 1.24$ & $21.43 \pm 0.98$ & $5.94 \pm 0.22$ \\
Chlorogenic acid & $1.81 \pm 0.07$ & $5.45 \pm 0.19$ & nd & $1.81 \pm 0.08$ \\
Caffeic acid & $2.53 \pm 0.12$ & $1.03 \pm 0.06$ & $0.17 \pm 0.01$ & $0.51 \pm 0.03$ \\
Siringic acid & $0.26 \pm 0.01$ & $0.51 \pm 0.02$ & $0.25 \pm 0.02$ & $4.17 \pm 0.15$ \\
Epicatechin & $2.67 \pm 0.11$ & $21.21 \pm 0.09$ & $3.90 \pm 0.18$ & $8.90 \pm 0.42$ \\
Coumaric acid & $1.21 \pm 0.05$ & $2.41 \pm 0.10$ & $1.07 \pm 0.08$ & $1.31 \pm 0.07$ \\
Ferulic acid & $6.12 \pm 0.26$ & $2.32 \pm 0.17$ & $4.16 \pm 0.21$ & $0.51 \pm 0.03$ \\
Sinapic acid & $7.68 \pm 0.31$ & $67.95 \pm 0.20$ & $75.28 \pm 0.26$ & $0.31 \pm 0.02$ \\
Salicylic acid & $10.73 \pm 0.48$ & $13.40 \pm 0.56$ & $22.41 \pm 0.81$ & $2.48 \pm 0.74$ \\
Rutin & $4.32 \pm 0.23$ & $22.16 \pm 1.02$ & $87.43 \pm 2.78$ & $13.99 \pm 0.58$ \\
Ellagic acid & $6.31 \pm 0.27$ & $26.52 \pm 1.11$ & $91.67 \pm 3.22$ & $236.63 \pm 9.44$ \\
Myricetin & $151.03 \pm 6.68$ & $6.14 \pm 0.25$ & $53.40 \pm 0.18$ & $105.05 \pm 4.46$ \\
trans-Cinnamic acid & $27.34 \pm 1.22$ & $1.66 \pm 0.07$ & $8.17 \pm 0.21$ & $9.58 \pm 0.30$ \\
Quercetin & $71.33 \pm 2.19$ & $3.33 \pm 0.15$ & $25.24 \pm 0.94$ & $5.31 \pm 0.21$ \\
\hline
\end{tabular}

Table 4. Mineral content of selected aromatic herbs $(\mathrm{mg} / 100 \mathrm{~g}$ fresh weight $)$

\begin{tabular}{cccc}
\hline Herbs & $\mathrm{Na}$ & $\mathrm{K}$ & $\mathrm{Ca}$ \\
\hline Parsley & $18.32 \pm 0.66$ & $654.31 \pm 24.11$ & $142.47 \pm 6.45$ \\
Dill & $15.14 \pm 0.34$ & $532.20 \pm 20.18$ & $195.19 \pm 8.18$ \\
Lovage & $12.26 \pm 0.41$ & $823.13 \pm 29.33$ & $230.88 \pm 5.68$ \\
Celery leaves & $15.72 \pm 0.69$ & $614.96 \pm 18.44$ & $224.32 \pm 9.21$ \\
\hline
\end{tabular}


Note the high content of ellagic acid found in celery leaves $(236.63 \mathrm{mg} / 100 \mathrm{~g})$, but also in lovage $(91.67 \mathrm{mg} / 100 \mathrm{~g})$, that explains, at least in part, the high antioxidant activity of these culinary herbs. Ellagic acid was also predominant in lovage whereas sinapic and vanillic acids were prevalent in dill. Among flavonoids, myricetin was predominat in parsley and celery leaves whereas rutin was predominant in dill and lovage. Myricetin is reported to have beneficial effects on renal functions (Ozcan et al., 2012) and to be a promising agent for the chemoprevention of skin cancer (Kang et al., 2011) while rutin is reported to have protective and antioxidant properties against ethanol induced gastric lesions (La Casa et al., 2000).

The content of minerals is an essential component of the nutritional value of foods. The content of $\mathrm{K}, \mathrm{Ca}, \mathrm{Mg}$ and $\mathrm{Na}$ of selected aromatic herbs is given in Table 4. There were significant differences in the mineral content of the aromatic plants analyzed, reflecting the specific genetic ability of the plants to accumulate minerals.

Among the four nutrient minerals investigated, the most abundant was $\mathrm{K}$ followed by $\mathrm{Ca}$ and $\mathrm{Mg}$. The potassium content ranged from $532 \mathrm{mg} / 100 \mathrm{~g}$ fw in dill to 823 $\mathrm{mg} / 100 \mathrm{~g} \mathrm{fw}$ in lovage while calcium content ranged from 142 $\mathrm{mg} / 100 \mathrm{~g}$ (parsley) to $231 \mathrm{mg} / 100 \mathrm{~g}$ (lovage). Lovage recorded the highest content of $\mathrm{K}, \mathrm{Ca}$ and $\mathrm{Mg}$ and the lowest $\mathrm{Na}$ content. The mineral content of the selected aromatic herbs low in sodium but high in potassium, calcium and magnesium - represents one of the main reasons why they would make an ideal component of the well-known Dietary Approaches to Stop Hypertension (DASH) diet, recommended for the prevention and treatment of elevated blood pressure levels (Sacks et al., 2001).

\section{Conclusions}

All the aromatic herbs analyzed recorded high levels of ascorbic acid and phenolic compounds, although significant differences were found between them. The richest in ascorbic acid has been shown to be parsley, with an extremely high content $(206.32 \mathrm{mg} / 100 \mathrm{~g})$, almost twice higher than lovage $(110.41 \mathrm{mg} / 100 \mathrm{~g})$. However, dill and celery leaves recorded also high values of the ascorbic acid content. In terms of phenolics content, the most valuable has been shown to be lovage, followed by dill and celery. The HPLC analysis revealed different phenolic profile of the investigated herbs. Myricetin was the main flavonoid in parsley, lovage and celery leaves, rutin was prevalent in lovage and dill while quercetin was the main flavonoid in parsley. High concentrations of ellagic acid have been found in lovage and celery leaves while dill presented high levels of sinapic and vanillic acids. A strong positive correlation was found between total phenolic content and antioxidant activity of the culinary aromatic plants analyzed. In addition, the high calcium, magnesium and potassium content found in these aromatic herbs, associated with the low content of sodium, may contribute to an improved nutritional status.

The results of this work demonstrated once again that parsley, dill, lovage and celery leaves represent a valuable source of antioxidant compounds. As a result, supplementing a balanced diet with these aromatic herbs may have beneficial health effects. Determination of the antioxidant potential of these herbs provides valuable information on the possible use of their extracts as a source of antioxidant compounds for the development of new products with health benefits.

\section{References}

Chanwitheesuk A, Teerawutgulrag A, Rakariyatham N (2005). Screening of antioxidant activity and antioxidant compounds of some edible plants of Thailand. Food Chemistry 92:491-497.

Čiž M, Cizova H, Denev P, Kratchanova M, Slavov A, Lojek A (2010). Different methods for control and comparison of the antioxidant properties of vegetables. Food Control 21:518-523.

Cosmulescu S, Trandafir I, Nour V, Botu M (2015). Total phenolic, flavonoid distribution and antioxidant capacity in skin, pulp and fruit extracts of plum cultivars. Journal of Food Biochemistry 39:6469.

Del Rio D, Rodriguez-Mateos A, Spencer JP, Tognolini M, Borges G Crozier A (2013). Dietary (poly)phenolics in human health: Structures, bioavailability, and evidence of protective effects against chronic diseases. Antioxidants \& Redox Signaling 18:1818-1892.

Fejes S, Blazovics A, Lemberkovics E, Petri G, Szoke E, Kery A (2000). Free radical scavenging and membrane protective effects of methanol extracted fractions of parsley. Acta Alimentaria 29:81-87.

Gunasekar M, Geemon K, Mariwala SJ (2012). Health benefits of bioactive molecules from spices and aromatic plants. Journal of Spices and Aromatic Crops 21(2):87-101.

Hinneburg I, Damien Dorman HJ, Hiltunen R (2006). Antioxidant activities of extracts from selected culinary herbs and spices. Food Chemistry 97:122-129.

Inouye S, Takizawa T, Yamaguchi H (2001). Antibacterial activity of essential oils and their major constituents against respiratory tract pathogens by gaseous contact. Journal of Antimicrobial Chemotherapy 47:565-573.

Leahu A, Damian C, Oroian M, Miclescu V, RopciucS (2013). Variation in content of antioxidant and free radical scavenging activity of basil (Ocimum basilicum), dill (Anethum graveolens) and parsley (Petroselinum sativum). Food and Environment Safety 12(4):347-353.

Kamel SM (2013). Effect of microwave treatments on some bioactive compounds of parsley (Petroselinum crispum) and dill (Anethum graveolens) leaves. Journal of Food Processing \& Technology 4:233, doi:10.4172/2157-7110.1000233.

Kiselova Y, Ivanova D, Chervenkov T, Gerova D, Galunska B, Yankova T (2006). Correlation between the in vitro antioxidant activity and polyphenol content of aqueous extracts from Bulgarian herbs. Phytotherapy Research 20:961-965.

Kreft I, Fabjan N, Germ M (2003). Rutin in buckwheat - Protection of plants and its importance for the production of functional food. Fagopyrum 20:7-11.

La Casa C, Villegas I, Lastra CA, Motilva V, Calero MJM (2000). Evidence for protective and antioxidant properties of rutin, a natural flavone, against ethanol induced gastric lesions. Journal of Ethnopharmacology 71:45-53.

Lisiewska Z, Kmiecik W, Korus A (2006). Content of vitamin C carotenoids, chlorophylls and polyphenols in green parts of dill (Anethum graveolens L.) depending on plant height. Journal of Food Composition and Analysis 19:134-140.

Mohammadzadeh S, Sharriatpanahi M, Hamedi M, Amanzadeh Y, Sadat Ebrahimi SE, Ostad SN (2007). Antioxidant power of Iranian propolis extract. Food Chemistry 103:729-733. 
184

Nour V, Trandafir I, Cosmulescu S (2013). HPLC determination of phenolic acids, flavonoids and juglone in walnut leaves. Journal of Chromatographic Science 51:883-890.

Oliveira I, Sousa A, Ferreira ICFR, Bento A, Estevinho L, Pereira JA (2008). Total phenols, antioxidant potential and antimicrobial activity of walnut (Juglans regia L.) green husks. Food and Chemical Toxicology 46:23262331.

Opara EI, Chohan M (2014). Culinary herbs and spices: their bioactive properties, the contribution of polyphenols and the challenges in deducing their true health benefits. International Journal of Molecular Sciences 15:19183-19202.

Ozcan F, Ozmen A, Akkaya B, Aliciguzel Y, Aslan M (2012). Beneficial effect of myricetin on renal functions in streptozotocin-induced diabetes. Clinical and Experimental Medicine 12:265-272.

Sacks FM, Svetkey LP,Vollmer WM, Appel LJ, Bray GA, Harsha D, ... Karanja N (2001). Effects on blood pressure of reduced dietary sodium and the dietary approaches to stop hypertension (DASH) diet. The New England Journal of Medicine 344(1):3-10.

Sakaldaş M, Aslım AȘ, Kuzucu CÖ, Kaynaş K (2010). The effects of modified atmosphere packaging and storage temperature on quality and biochemical properties of dill (Anethum graveolens) leaves. Journal of Food, Agriculture \& Environment 8(3\&4):21-25.

Shan B, Cai YZ, Sun M, Corke H (2005). Antioxidant capacity of 26 spice extracts and characterization of their phenolic constituents. Journal of Agricultural and Food Chemistry 53:7749-7759.
Singleton VL, Rossi JA (1965). Colorimetry of total phenolics with phosphomolybdic-phosphotungstic acid reagents. American Journal of Enology and Viticulture 16:144158.

Shobana S, Akhilender Naidu K (2000). Antioxidant activity of selected Indian spices. Prostaglandins Leukotrienes and Essential Fatty Acids 62:107-110.

Vallverdu-Queralt A, Regueiro J, Martinez-Huelamo M, Alvarenga JFR, Leal LN, Lamuela-Raventos RM (2014). A comprehensive study on the phenolic profile of widely used culinary herbs and spices: rosemary, thyme, oregano, cinnamon, cumin and bay. Food Chemistry 154:299307.

Wu TT, Hwang BR, Cho EJ (2011). Scavenging effect of extract from Perilla frutescens and rosmarinic acid from free radical and lipid peroxidation. Journal of Food Science and Nutrition 16:224-229.

Yen GC, Duh PD, Tsai HL (2002). Antioxidant and pro-oxidant properties of ascorbic acid and gallic acid. Food Chemistry 79:307-313.

Zenoozian MS (2011). Effect of modified atmosphere packaging on quality changes of fresh parsley, spinach and dill. Proceedings of the 2nd International Conference on Environmental Science and Technology IPCBEE, Singapore, Vol 6:76-79.

Zheng W, Wang S (2001). Antioxidant activity and phenolic composition in selected herbs. Journal of Agricultural and Food Chemistry 49:51655170. 